\title{
Optimism mediates the relationships between meaning in life and subjective and psychological well-being among late adolescents
}

\author{
Dariusz $\operatorname{Krok}^{1 \cdot A, B, C, D, E}$, Ewa Telka ${ }^{2 \cdot A, D, F}$ \\ 1: University of Opole, Opole, Poland \\ 2: Department of Radiotherapy, Cancer Center and Institute of Oncology, Gliwice, Poland
}

BACKGROUND

The concepts of meaning in life and well-being appear to have structural and functional connections, which become even more noticeable when examining their role in individuals' daily functioning. One of the prospective variables which can play a mediational role between meaning in life and subjective and psychological well-being may be optimism, which also holds an important motivational value for young people. The aim of this study was to examine the predictive value of meaning in life and optimism, and indirect effects between meaning in life and subjective and psychological well-being among Polish late adolescents within the self-concordant model.

\section{PARTICIPANTS AND PROCEDURE}

A total of 205 participants (104 female and 101 male; mean age $=18.31$ years) from Poland completed five scales measuring meaning in life, optimism, and well-being. They completed the following measures: the Personal Meaning Profile, the Life Orientation Test-Revised, the Satisfaction
With Life Scale, the Positive and Negative Affect Schedule, and the Psychological Well-Being Scale.

RESULTS

Results of SEM analysis demonstrated that meaning in life and optimism were positively related to both subjective and psychological well-being. Optimism served as a partial mediator in the relationships between meaning in life and subjective and psychological well-being.

\section{CONCLUSIONS}

The mediating effect of optimism was explained within the self-concordance model. Consistent with the model, meaning in life had an enhancing effect on late adolescents' experience of optimism on the basis of self-concordant goals, which in turn led to improving their subjective and psychological well-being.

KEY WORDS

meaning in life; optimism; subjective well-being; psychological well-being; late adolescents

CORReSPonding AUthor - Prof. Dariusz Krok, University of Opole, 1A Drzymały Str., 45-342 Opole, Poland, e-mail: dkrok@uni.opole.pl

Authors' CONTRibution - A: Study design - B: Data collection - C: Statistical analysis - D: Data interpretation . E: Manuscript preparation · F: Literature search · G: Funds collection

TO CITE THIS ARTICLE - Krok, D., \& Telka, E. (2019). Optimism mediates the relationships between meaning in life and

subjective and psychological well-being among late adolescents. Current Issues in Personality Psychology, 7(1), 32-42. RECEIVED 27.04.2018 · REVIEWED 17.10.2018 · ACCEPTED 31.10.2018 · PUBLISHED 05.12.2018 


\section{BACKGROUND}

Research into well-being has generated a substantial amount of interest in different areas of psychology. Although outcome studies have demonstrated that personality traits are related to particular facets of well-being, the pattern of these relationships tends to be complex and depends on both the nature of personality traits and specific dimensions of well-being (Garcia, 2011; Sheldon \& Hoon, 2013). Two important factors that have been investigated in relation to well-being are optimism and meaning in life, which proved to play a significant role in determining one's life satisfaction and happiness (Ferguson \& Goodwin, 2010; Ho, Cheung, \& Cheung, 2010). Yet there have been relatively few attempts to examine direct and indirect links between optimism, meaning in life, and well-being, which are most likely to be subject to mediational patterns. Well-being also needs to be examined from different perspectives as it encompasses a broad spectrum of dimensions reflecting the sphere of human happiness (Seligman, 2012). In addition, few studies (e.g., Brassai, Piko, \& Steger, 2011; Krok, 2015a) have focused exclusively on late adolescents, for whom finding meaning in life and happiness are the critical issues during this developmental period, as young people are in the stage of identity vs. role confusion (Erikson, 1982). Late adolescence generally encompasses the latter part of the teenage years, broadly between the ages of 16 and 20 (Shaffer \& Kipp, 2013). This period involves important dynamic psychological changes, such as integrating human identity, acquiring abstract thinking skills, searching for a deeper view of life and social issues, and developing romantic relationships.

\section{RELATIONSHIPS BETWEEN MEANING IN LIFE AND WELL-BEING}

The concepts of meaning in life and well-being appear to have structural and functional connections, which become even more noticeable when examining their role in individuals' daily functioning. Although meaning in life has been operationalized in different ways, across the studies most definitions encompass the notions of purpose and significance. Meaning in life is generally perceived in terms of a unique purpose or overarching aim for human life connected with values (Frankl, 1969), a sense of coherence or understanding of existence (Baumeister, 1991), and personal goals pursued by individuals (Emmons, 2003).

In this study, meaning in life is conceptualized as a cognitive multidimensional construct which reflects meaningful goals and motives for goal striving. It is primarily rooted in human cognition and differs between individuals. This stance is presented by Wong (1998, 2012), who proposed the concept of meaning in life as an individually constructed cognitive system, which endows life with personal significance. Meaning in life belongs to the category of personal meaning which consists of beliefs and ideas held by people that reflect their sense of purpose and significance (Reker \& Wong, 2012; Wong, 2012). According to Wong (1998, 2012), meaning in life comprises seven domains: achievement (pursuit and attainment of significant life goals), relationship (general social adeptness), religion (having affirmative beliefs about relationships with the divine), self-transcendence (engagement in selfless pursuits), self-acceptance (a humble acceptance of one's limitations), intimacy (having emotionally close relationships), and fair treatment (perceiving a degree of justice in life). People often treat meaning in life as a cognitive map that enables them to interpret life events in terms of purpose and significance.

A different approach to meaning in life is proposed by Steger (2009), who defines meaning in life as "the extent to which people comprehend, make sense of, or see significance in their lives, accompanied by the degree to which they perceive themselves to have purpose, mission, or overarching aim in life" (p. 682). Meaning is a superordinate term that encompasses two main factors: comprehension and purpose (Steger, 2012). The first factor reflects the human ability to make sense of and understand one's life. The second factor denotes overarching and long-term life aspirations that are self-concordant and stimulate related activity. Meaning in life can be viewed in two different dimensions: (1) presence of meaning - which concerns the degree to which individuals perceive their lives as significant and meaningful and (2) search for meaning - which reflects the degree to which people are engaged in a search for meaning in life.

There has been research indicating that meaning in life is linked to well-being conceptualized within both subjective and psychological perspectives (Krok, 2014; Thoits, 2012). Subjective well-being (SWB) reflects the hedonic aspect of well-being which consists of the pursuit of happiness and a pleasant life. It is conceptualized as a person's cognitive and affective evaluations and comprises three components: life satisfaction (referring to satisfaction with life as a whole), positive affect, and negative affect (Diener, 1984; Diener, Oishi, \& Lucas, 2009). Psychological well-being (PWB) is based on an eudaimonic approach which stresses the fulfillment of human potential and a meaningful life. It focuses on growing and developing as a person, pursuing meaningful goals and values, and coping with life challenges (Ryff, 1989; Ryff $\&$ Singer, 2008). These two perspectives reflect different conceptual approaches to examining the sphere of well-being and happiness.

Several studies have shown that meaning in life contributes to well-being and happiness. Individuals 
who were convinced that their lives had meaning and purpose were found to be happier (Debats, Lubbe, \& Wezeman, 1993) and reported higher levels of life satisfaction (Steger, Kashdan, Sullivan, \& Lorentz, 2008). Meaning of life was also associated with positive affect and emotions, which are often regarded as an emotional dimension of subjective well-being (Diener, 2009). Individuals who reported high levels of meaning tended to experience stronger positive affect (King, Hicks, Krull, \& Del Gaiso, 2006) and less negative affect (Machell, Kashdan, Short, \& Nezlek, 2015), depression and anxiety (Debats et al., 1993). The results of a meta-analysis conducted by Pinquart (2002) revealed that the correlation between meaning in life and positive affect among older adults was .47.

Meaning in life was also found to be related to global happiness (Ryff \& Singer, 2008), general wellbeing among Chinese adolescents (Ho et al., 2010), and psychological well-being among people coping with stress (Krok, 2015b). Additionally, meaning in life appears to be a strong predictor of psychological health among adolescents (Brassai et al., 2011). The results suggest that meaning in life is important for individuals' well-being, because it can facilitate positive human functioning and imbue life with a sense of purpose and significance. Yet there is little evidence explaining how meaning in life conceptualized in terms of personal meaning may be related to specific dimensions of subjective and psychological well-being.

\section{THE MEDIATIONAL FUNCTION OF OPTIMISM}

Although research has confirmed the relationships between meaning in life and well-being, there are still few studies examining the underlying mechanisms and potential mediators. One of the prospective variables which can play a mediational role between meaning in life and subjective and psychological well-being may be optimism, which also holds an important motivational value for young people. Optimism (vs. pessimism) is a dimension of personality defined by the expectation that good (vs. bad) things will happen to oneself in important domains of life (Scheier \& Carver, 2009). Generalized optimism pertains to the person's entire life, rather than to just one domain or another.

The premise regarding a mediational role of optimism is based on the previous research which has demonstrated that optimism is related to meaning in life among university and community college staff and students (Steger, Frazier, Oishi, \& Kaler, 2006) and adolescents (Ho et al., 2010). There has also been substantial evidence indicating relationships between optimism and well-being. Testing a cognitive-affective model of psychological adjustment, Chang and Sanna (2001) found that optimism significantly predicted positive affective aspects of subjective well-being in middle-aged adults. Optimism was also connected with life satisfaction, low negative emotions, and low depression (Ferguson \& Goodwin, 2010), and with positive affect and adversely with negative affect among adolescents (Sulkers et al., 2013). These findings imply that optimism can be related to both meaning in life and well-being indicators among late adolescents. Their connections can be based on self-regulatory activities related to adaptive management of personal goals, which are embedded in all these constructs and have intrinsic motivational value. The importance of goal attainment for successful development in late adolescence is strongly emphasized by the notion of developmental tasks. According to Erikson (1968), the successful attainment of developmental tasks in young people leads to successful development, life satisfaction, and finding a sense of purpose, whereas failure to solve developmental tasks may result in dissatisfaction and social problems.

Meaning in life may facilitate subjective and psychological well-being, mediated by a person's optimistic disposition on the basis of attainable goals, which are at the core of all these constructs. This assumption can be more deeply understood within the framework of the self-concordance model (Sheldon \& Houser-Marko, 2001), which offers a valuable conceptual basis for examining the relations between meaning, optimism, and well-being, and has also been conducive to research on well-being (Sheldon $\&$ Cooper, 2008). The self-concordance model focuses on how goals contribute to well-being in the spheres of the motives underlying personal goal striving, the influences of goal motives on goal attainment, and their consequences for well-being. Self-concordance theory predicts that individuals are happiest when stated goals match enduring interests and values.

The model posits that autonomous goal motivation would predict positive expectancies, which can finally predict greater well-being (Sheldon \& Cooper, 2008). When individuals strive because of strong interest or because of self-identified personal convictions, the goals tend to be well integrated with the self. Possessing meaningful goals and engaging in meaning-making activities lead to experiencing greater self-concordance, which in turn increases the frequency of goal-oriented activities. Consequently, self-concordant goals are likely to receive sustained effort over time, be more attainable, and as such are more satisfying (Sheldon \& Houser-Marko, 2001; Sheldon et al., 2004). Striving for goals has motivational value for well-being. The more frequently people attain goals, the greater positive expectancies (i.e., optimism) they have. As a consequence, the attainment of goals which are congruent with an individual's values and interests will elevate wellbeing because they offer substantial support toward 
personal growth and development. Therefore, the association between attaining meaningful goals and outcomes (i.e., well-being) is likely to be mediated by positive expectancies (i.e., optimism).

Previous research has pointed to meditational effects of optimism in the relationships between meaning-oriented constructs and well-being. Ho and his colleagues (2010) found that optimism served as a partial mediator in the relationships between meaning in life and both positive and negative aspects of well-being among Chinese adolescents. However, the mediating role of optimism did not differ across gender. There were also unexplained differences in mediational effects of optimism for positive vs. negative well-being, with stronger results for negative wellbeing. In addition, the concept of well-being in this study was only operationalized in subjective terms as the level of adolescents' global life satisfaction in specific domains (i.e. family, friend, health, school, and self) in the Chinese context. Research conducted on late adolescents in Poland found the mediating role of optimism in the relations between sense of coherence and subjective and psychological well-being (Krok, 2015a).

Optimism has also been found to mediate between several variables associated with meaning in life and well-being. It partially mediated the relation between self-efficacy and well-being (Karademas, 2006). Additionally, optimism predicted a higher level of life satisfaction and lower level of depressive symptoms, which both served as indicators of well-being. Research conducted by Krok (2015a) demonstrated that optimism served as a partial mediator in the relationships between sense of coherence and subjective and psychological well-being among late adolescents. As the concept of meaning in life bears conspicuous resemblance to sense of coherence (they both encompass ultimate purpose and meaning), optimism can be expected to mediate the relationships between meaning in life and well-being.

\section{THE PRESENT STUDY}

Previous research has found substantiated evidence for the model proposed in the current study, in which the mediating effects of optimism on the relationships between meaning in life and well-being were investigated in a sample of late adolescents. The present study extends previous research by incorporating multiple measures of well-being in young people to capture the complex nature of human happiness. The primary goal of this study is to examine the predictive value of meaning in life and optimism, and indirect effects between meaning in life and subjective and psychological well-being among Polish late adolescents within the self-concordant model. Three specific hypothesis were proposed in the present study: Hypothesis 1: Meaning in life and optimism will be positively related to subjective and psychological well-being; Hypothesis 2: Optimism will mediate the relationships between meaning in life and subjective well-being on the basis of cognitive and affective domains; Hypothesis 3: Optimism will be a mediator between meaning in life and psychological well-being on the basis of goals and values.

\section{PARTICIPANTS AND PROCEDURE}

\section{PARTICIPANTS}

Two hundred and five late adolescents (104 females, and 101 males) participated in this study. Ages ranged from 16 to 20 , with a mean age of 18.31 years $(S D=1.09)$. The sample was a representative group of Polish late adolescents in terms of gender, social status, and age. The data were collected from a stratified sample of 6 colleges and 10 workplaces in southern parts of Poland, aiming to cover a wide range of characteristics (e.g. geographic location, schools' academic standing, socio-cultural and socio-economic backgrounds) to ensure representativeness of the sample. Despite the high participation of centers in the study, the sample is not very large due to the fact that participants in colleges and workplaces were randomly selected.

\section{PROCEDURE}

The participants were selected at random in proportions equivalent to the population of late adolescents. They were invited to participate in the study on a voluntary basis. The study was anonymous and the participants were asked to complete a questionnaire packet either in the classroom (students) or at home (those in jobs). To encourage honest and objective answers, the participants were told their responses were anonymous and there were no right or wrong answers to any of the questions. Informed consent for those students who were under 18 years of age was obtained from both them and their parents. After completing the questionnaires the participants were informed about the aim of the study. The following questionnaires were used in the current research. They were all Polish adapted versions.

Meaning in life. The Personal Meaning Profile (PMP) (Wong, 1998) evaluates personal meaning that is regarded as an individually constructed cognitive system, which endows life with personal significance. The scale measures the level of meaning in life reported by respondents in seven domains: achievement, relationship, religion, self-transcendence, selfacceptance, intimacy, and fair treatment. A total PMP score can be computed by summing the seven 
subscale scores. The questionnaire contains 57 items evaluated on a 7-point Likert scale from 1 (not at all) to 7 (a great deal). Higher scores indicate a higher level of meaning in life. The Cronbach's $\alpha$ coefficients for the present study ranged from .67 to .91 for the subscales and .79 for the total score.

Optimism. The Life Orientation Test-Revised (LOT-R; Scheier, Carver, \& Bridges, 1994) was used to assess the participants' level of optimism. It is a 10-item scale, with 4 filter items and 6 scale items. A total score can be calculated by summing the three positively worded and three negatively worded items (these are reverse coded). Answers are given on a 5-point scale, ranging from strongly agree to strongly disagree. Higher scores indicate more optimism. The Cronbach's $\alpha$ coefficient for the present study was .76.

Subjective well-being. In order to assess subjective well-being two scales measuring its cognitive and affective dimensions were used. The Satisfaction With Life Scale (SWLS; Diener, Emmons, Larsen, \& Griffin, 1985) is a widely used measure which evaluates the cognitive dimension of subjective well-being. It consists of five items rated from 1 (absolutely untrue) to 7 (absolutely true). Higher scores indicate greater satisfaction with life. The Cronbach's $\alpha$ coefficient for the present study was .84. The Positive and Negative Affect Schedule (PANAS-X; Watson $\&$ Clark, 1994) measures the affective component of subjective well-being in two main domains, i.e. positive and negative affect, as well as in 11 more specific affects. In the current research only positive and negative affect subscales were used (10 items in each subscale) which are measured using a 5-point scale. The Cronbach's $\alpha$ coefficients for the subscales in the current study were .84 and .83 , respectively.

Psychological well-being. The Psychological WellBeing Scale (PWB) is a 42-item questionnaire that evaluates the level of individuals' development and self-realization on a 6-point scale (Ryff \& Singer, 2008). It comprises six subscales: autonomy, environmental mastery, personal growth, positive relations with others, purpose in life, and self-acceptance. Participants respond to the items on a 6-point Likert scale ranging from 1 (strongly disagree) to 7 (strongly agree). A total PWB score was computed by summing the six subscale scores. The Cronbach's $\alpha$ coefficients in this sample ranged from .71 to .91 for the subscales and .85 for the total score.

\section{DATA ANALYSIS}

To examine the statistical differences in correlation between meaning in life, subjective, and psychological well-being, tests calculating the difference between correlation coefficients were conducted. Next, structural equation modeling analyses (SEM) were used to investigate the influence of meaning in life on subjective and psychological well-being and the possible mediational role of optimism. The two-step procedure recommended by Anderson and Gerbing (1988) was used to analyze the mediational effects of optimism in the relationships between meaning in life and subjective and psychological well-being. First, confirmatory factor analysis was used to determine a measurement model with an acceptable fit to the data. Provided an acceptable measurement model was developed, the structural model using the maximum likelihood estimation in the AMOS 21.0 program was tested.

To test for the statistical significance of the mediation effects of optimism on the relationships between meaning in life and subjective and psychological well-being, standard ML bootstrapping was performed (a bootstrap sample of 1000 was specified). According to the recommendations of bootstrapping as a resampling method to estimate mediation, if the 95\% confidence interval (CI) does not include zero, it means a significant indirect effect at the level of .05 (Preacher \& Hayes, 2008).

\section{RESULTS}

\section{RELATIONS AMONG MEANING IN LIFE, OPTIMISM, AND SUBJECTIVE AND PSYCHOLOGICAL WELL-BEING}

First, correlational analysis was used to examine the relationships between meaning in life, optimism, subjective well-being, and psychological well-being. The results are presented in Table 1 .

As shown, all the correlations among the examined variables were found to be statistically significant. Meaning in life was positively associated with optimism, life satisfaction, positive affect, and psychological well-being, and negatively associated with negative affect. Optimism was positively related to life satisfaction, positive affect, and psychological well-being, and negatively related to negative affect. As regards subjective well-being scales, life satisfaction and positive affect were positively correlated with psychological well-being, while negative affect was negatively correlated with psychological well-being.

There was a significant difference between the correlations of meaning in life with life satisfaction and meaning in life with negative affect $(z=8.39, p<.001)$, but not with positive affect $(z=1.77, p<.083)$. Furthermore, the correlation of meaning in life with psychological well-being significantly differed from the correlation of meaning in life with positive affect $(z=3.17, p<.001)$, and with negative affect $(z=9.03$, $p<.001$ ), but not from the correlation of meaning in life with life satisfaction $(z=1.37, p<.167)$. 
Table 1

Correlations among meaning in life, optimism, subjective well-being, and psychological well-being

\begin{tabular}{|c|c|c|c|c|c|c|}
\hline & 1 & 2 & 3 & 4 & 5 & 6 \\
\hline 1. Meaning in life & - & & & & & \\
\hline 2. Optimism & $.43^{* * *}$ & - & & & & \\
\hline 3. Life satisfaction & $.53^{* * *}$ & $.49^{* * *}$ & - & & & \\
\hline 4. Positive affect & $.45^{* * *}$ & $.49^{* * *}$ & $.55^{* * *}$ & - & & \\
\hline 5. Negative affect & $-.37^{* * *}$ & $-.43^{* * *}$ & $-.46^{* * *}$ & $-.31^{* * *}$ & - & \\
\hline 6. Psychological well-being & $.60^{* * *}$ & $.55^{* * *}$ & $.57^{* * *}$ & $.66^{* * *}$ & $-.54^{* * *}$ & - \\
\hline
\end{tabular}
Note. ${ }^{* * *} p<.001$.

\section{THE MEDIATIONAL EFFECT OF OPTIMISM ON THE RELATIONSHIP OF MEANING IN LIFE AND WELL-BEING}

An initial test of the measurement model revealed a satisfactory fit to the data: $\chi^{2}=68.84, p<.001$; $\mathrm{NFI}=.98 ; \mathrm{CFI}=.99$; RMSEA $=.04$. All the factor loadings for the indicators on the latent variable (i.e. subjective well-being) were found to be significant $(p<.001)$, which implies that all the latent factors were well represented by their respective indicators. The mediation model of optimism in the relationship between meaning in life and subjective and psychological well-being demonstrated a satisfactory fit to the data, with $\chi^{2}=22.34, p<.05$; NFI = .98; CFI = .99; RMSEA $=.05$ (Figure 1).

The SEM results showed a significant direct effect of meaning in life on subjective well-being (.43, $p<.001)$, psychological well-being $(.44, p<.001)$, and optimism $(.43, p<.001)$. The SEM results also demonstrated a significant effect of optimism on subjective well-being $(.50, p<.001)$ and psychological well-being $(.37, p<.001)$. Indirect effects were also examined. There was a significant drop in the total effect of meaning in life on subjective well-being (.22, $p<.05)$ and psychological well-being $(.16, p<.05)$ after controlling for optimism, indicating a significant indirect effect of meaning in life on subjective and psychological well-being. The predictive power of meaning in life on the cognitive and affective dimensions of subjective well-being after taking into account the mediational effect of optimism was slightly different for life satisfaction $(.44, p<.05)$, positive affect $(.48$, $p<.001)$, and negative affect $(-.40, p<.001)$.

As shown in Table 2, the bootstrap CI results exclude zero, which suggests that meaning in life exerted a significant indirect effect on subjective and psychological well-being through optimism.

The results of the mediation model of optimism were cross-validated by using multigroup analyses to test for equivalence of the mediation between boys and girls. The results demonstrated that the path coefficients for optimism were non-statistical across gender, which implies that the mediating role of optimism did not differ across gender in the late adolescent sample.

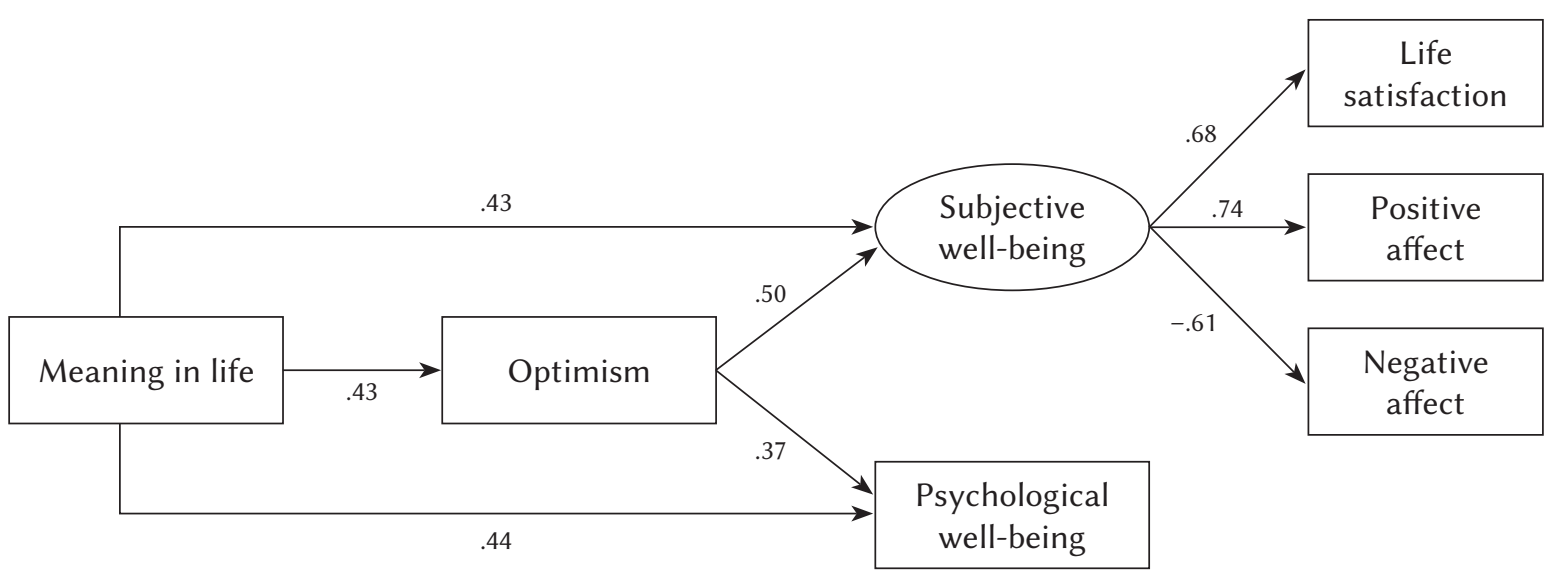

Figure 1. The mediational model of optimism in the relation between meaning in life and subjective and psychological well-being. 
Table 2

Standardized indirect effects and 95\% confidence intervals

\begin{tabular}{|c|c|c|c|}
\hline \multirow[t]{2}{*}{ Model pathways } & \multirow[t]{2}{*}{ Estimated } & \multicolumn{2}{|c|}{$95 \% \mathrm{Cl}$} \\
\hline & & Lower & Upper \\
\hline Meaning in life $\rightarrow$ optimism $\rightarrow$ subjective well-being & $.22^{\mathrm{a}}$ & .16 & .32 \\
\hline Meaning in life $\rightarrow$ optimism $\rightarrow$ psychological well-being & $.16^{\mathrm{a}}$ & .11 & .21 \\
\hline
\end{tabular}

\section{DISCUSSION}

The current study aimed to investigate the mediational role of optimism in the relationship between meaning in life and subjective and psychological well-being among late adolescents. Using correlational and SEM analyses, the study contributes to the existing literature in two major ways. First, it demonstrates that meaning in life and optimism are important predictors of young people's subjective and psychological well-being. Second, this study is the first to show that optimism mediates the relationship between meaning in life and well-being conceptualized in terms of subjective and psychological happiness among late adolescents. It suggests that young people who derive meaning in life from their beliefs, values, and activities have a higher level of optimism, which in turn increases their subjective and psychological well-being.

\section{MEANING IN LIFE, OPTIMISM, AND SUBJECTIVE AND PSYCHOLOGICAL WELL-BEING}

As expected, the correlational results proved that meaning in life and optimism had significant associations with both subjective and psychological well-being among late adolescents. These results are consistent with other cross-sectional studies that reported relationships between meaning in life, optimism, and indicators of well-being in adolescents and other age groups (Debats et al., 1993; Ho et al., 2010; Krok, 2014). These findings verify the first hypothesis that expected such relationships. Meaning in life and optimism had positive associations with psychological well-being and with two dimensions of subjective well-being: life satisfaction and positive affect. In contrast, there were negative associations between meaning in life, optimism, and negative affect.

These results are important as they point out that possessing meaning-oriented structures, the expectation of a positive outcome, and favorable views regarding future events play an important role in adolescence, as the pursuit of meaningful goals and their attainment are central components of adaptive self-regulation processes for young people (Brassai et al., 2011; Orejudo, Puyuelo, Fernández-Turrado, \& Ramos, 2012). Meaning in life and optimism enable youths to strive for meaningful goals, construe the categories of purpose and significance, and face adverse life events. However, the current study extends the previous research by showing that meaningful cognitive structures and optimistic viewpoints are beneficial for young people for both experiencing life in terms of pleasure and enjoyable emotions (subjective well-being), and fulfilling one's potential and striving for meaningful goals and values (psychological well-being). A high level of meaning in life and an optimistic approach tend to effectively contribute to the process of forming a satisfactory and fulfilled quality of life during this developmental period.

The strong positive correlations of meaning in life and optimism with subjective and psychological well-being among late adolescents that emerged in this study are also reinforced by observations from other studies (Steger et al., 2006). Late adolescents are particularly sensitive to searching for purpose, values, and future perspectives (Shaffer \& Kipp, 2013). As a consequence, meaning in life and optimism can be beneficial to experiencing positive cognitive and emotional states, both of a hedonic and eudaimonic nature. Meaningful and optimistic attitudes provide young people with necessary life skills, which improve their ability to overcome adversities and attain happiness and life fulfillment. As proposed by Scheier and Carver (2009), optimists may use more constructive coping strategies that enable them to deal more effectively with stressful events and make them more resistant to psychological distress. The reason appears to lie in their predominantly positive cognitive approach to the future. Optimists are people who expect good things to happen in their life. Therefore, being confident and assured about the future, optimists continue trying to achieve goals, even when they are difficult to reach.

\section{THE MEDIATING MODEL OF OPTIMISM}

The central result in this study focuses on the mediational role played by optimism. Consistent with the 
literature suggesting a potential mediation effect of optimism between meaning in life and well-being (Ho et al., 2010; Krok, 2015a), the current study demonstrated that optimism mediated these relationships for both subjective and psychological well-being. Extending the literature, this new evidence is among the first to explain how meaning in life may affect different dimensions of well-being through the meditational influence of dispositional optimism. Although previous research showed that optimism was a mediator for well-being, it neither specified the character of those relations (Karademas, 2006) nor examined subjective and psychological well-being, using instead the concept of global life satisfaction (Ho et al., 2010). The results of SEM analysis obtained in the current study demonstrated that optimism had both direct and indirect effects on subjective and psychological wellbeing, suggesting that the personality trait reflecting positive expectations for the future served as a partial mediator. Although some studies have found that meaning in life is a significant predictor of well-being (Steger et al., 2008, Thoits, 2012), the current results indicate that it might not be a key predictor in late adolescents. These findings confirm the second and third hypotheses which assumed those mediational relationships.

As evidenced in recent studies, optimism mediated relationships between social factors (e.g. social support, leadership styles) and well-being (Ekas, Lickenbrock, \& Whitman, 2010). This study extends the previous results by pointing out that the mediational effect of optimism also occurs between constructs reflecting a sense of purpose and significance, and different dimensions of well-being. The finding may indicate a strong interconnection between meaningoriented structures, expectancies pertaining to the person's entire life space, and cognitive and affective processes responsible for overall happiness. In this view, as a part of optimal human functioning, meaning in life and optimism are protective factors that sustain and enhance subjective and psychological well-being.

The current study also sheds new light on the role played by meaning in life in shaping young people's well-being. It suggests that meaning in life should not be perceived as a self-sufficient and independent resource bolstering the developmental processes of late adolescents' well-being, but as a factor that operates in association with dispositional optimism. This interpretation is in line with results obtained by Ho and colleagues (2010) in which optimism served as a partial mediator in the relationships between meaning in life and both positive and negative aspects of wellbeing. The complex relations among meaning in life, optimism and well-being are crucial for late adolescents whose daily experiences often consist in striving to attain a sense of purpose and significance, forming multiple plans and ideas, and completing developmental tasks (Shaffer \& Kipp, 2013). Meaning- oriented and optimistic attitudes tend to enhance pleasure-oriented happiness (subjective well-being) and existential happiness (psychological well-being), which in turn enable them to achieve meaningful goals and cope with life challenges. Thus, the present study provides an important opportunity to examine several important aspects of well-being in a single study, helping to create a more holistic impression of the role played by meaning in life and optimism in positive functioning.

The mediational role of optimism may be more fully understood in the framework of the self-concordance model. According to the model, the attainment of meaningful goals congruent with an individual's values and interests leads to experiencing more positive affective states, which in turn elevate well-being and provide support toward personal growth and development. This explanation is buttressed by research conducted by Ju and colleagues (2013), in which greater optimism was associated with a higher sense of meaning in life. Optimism was also found to be a predictor of both subjective and psychological well-being among elderly people (Ferguson \& Goodwin, 2010).

The current study suggests that optimism may be mediationally linked to meaning in life in late adolescents, because of its relation to goal-directed behavior, which is especially important for young people. While going through the transition to adulthood, late adolescents attempt to formulate personal goals that are both satisfactory and beneficial for their future life. Young people strive to attain these goals through specific actions and activities which benefit their well-being. This interpretation is in line with the suggestions proposed by Scheier and Carver (2009) within the self-concordance model that positive affects are an indication that an individual's life is purposeful in the sense that the individual is advancing towards valued goals. The pattern found in the present study indicates that meaning in life is central to optimism and contributes to a satisfying and fulfilling life on the basis of meaningful goals.

The mediating effect of optimism between meaning in life and well-being also suggests that meaning in life has an enhancing effect on late adolescents' experience of optimism, and this has the consequence of improving their subjective and psychological well-being. Steger $(2009,2012)$ suggests that the comprehension and purpose components of meaning in life have intrinsic motivational value that can help people resolve difficult tasks, develop future resilience to psychological distress, and cultivate a wider existential perspective than their momentary experiences. This in turn facilitates the pursuit of self-concordant goals promoting sustained effort over time and stimulating greater progress in goals, which increases positive expectancies for the future and consequently enhances optimism (Sheldon \& Hoon, 2013). As a result, these processes will lead 
to more satisfying daily experiences in young people, fostering positive changes in their global well-being. Meaning in life and optimism may thus operate simultaneously in changing well-being as they enable individuals to endow essential parts of their life with personal significance and attain goals which are embedded in subjective and psychological well-being.

\section{LIMITATIONS}

It must be acknowledged that the study has certain limitations. First, the sample size used in our research was rather small, which limits the generalizability of the results. Future research should examine a larger sample of adolescents, which will increase its accuracy. Although SEM analysis expresses the linear causal relationship between separate sets of constructs, causality remains ambiguous with regard to the direction of relations between meaning in life, optimism, and subjective and psychological well-being, because of the cross-sectional design. In addition, Byrne (2016) states that SEM can be performed with a minimum of 200 subjects. As our sample was just above the limit (205 participants), the SEM statistical results must be interpreted with caution. Second, only one indicator of subjective and psychological well-being was used. As studies of adolescents' wellbeing showed different results with different kinds of instruments (González-Carrasco, Casas, Malo, Viñas, \& Dinisman, 2017; González-Carrasco et al., 2017), future research should aim to use a wider variety of well-being measures.

Third, only the measure of dispositional optimism was used. In addition to the very common and methodologically useful LOT-R, there are also other measures to examine different facets of optimism, e.g. specific positive and negative future expectancies or optimistic explanatory styles (Orejudo et al., 2012). Including measures that encompass a different set of optimism characteristics than dispositional optimism could broaden our understanding of people's approaches to positive expectancies for the future. Fourth, the sample used in this study comprised late adolescents who did not experience severe mental difficulties. It could be that meaning in life and optimism in young people experiencing serious mental problems have a different effect on their well-being. Future studies examining the above-mentioned factors should also focus on specific groups of late adolescents characterized by various mental difficulties.

\section{CONCLUSIONS}

Despite the limitations, examining relationships between meaning in life, optimism, and subjective and psychological well-being proved fruitful as it shed new light on the role of these factors for late adolescents. The results of this study provide clear evidence that optimism mediated the relationships between meaning in life and both subjective and psychological well-being among late adolescents. These pathways appear important to understanding the processes through which different dimensions of well-being may be shaped and increased. Meaning in life has an enhancing effect on late adolescents' experience of optimism on the basis of self-concordant goals, which in turn leads to improving their subjective and psychological well-being. As such, this study lays a strong foundation for further research exploring personality traits related to meaning-oriented structures and expectancy-related beliefs in the context of well-being.

\section{References}

Anderson, J. C., \& Gerbing, D. W. (1988). Structural equation modeling in practice. A review and recommended two-step approach. Psychological Bulletin, 103, 411-423. doi: http://dx.doi.org/ 10.1037/0033-2909.103.3.411

Baumeister, R. (1991). Meanings of life. New York: Guilford.

Brassai, L., Piko, B. F., \& Steger, M. F. (2011). Meaning in life: Is it a protective factor for adolescents' psychological health? International Journal of Behavioral Medicine, 18, 44-51. doi: http://dx.doi. org/10.1007/s12529-010-9089-6

Byrne, B. M. (2016). Structural equation modeling with AMOS: Basic concepts, applications, and programming. New York: Routledge.

Chang, E. C., \& Sanna, L. J. (2001). Optimism, pessimism, and positive and negative affectivity in middle-aged adults: a test of a cognitive-affective model of psychological adjustment. Psychology and Aging, 16, 524-531. doi: http://dx.doi. org/10.1037/0882-7974.16.3.524

Debats, D. L., van der Lubbe, P. M., \& Wezeman, F. R. A. (1993). On the psychometric properties of the Life Regard Index (LRI): A measure of meaningful life. Personality and Individual Differences, 14, 337-345. doi: http://dx.doi.org/10.1016/0191-8869(93)90132-M

Diener, E. (1984). Subjective well-being. Psychological Bulletin, 95, 542-575. doi: http://dx.doi. org/10.1037/0033-2909.95.3.542

Diener, E. (2009). The science of well-being. Social Indicators Research Series, 37, 11-58. doi: http:// dx.doi.org/10.1007/978-90-481-2350-6

Diener, E. D., Emmons, R. A., Larsen, R. J., \& Griffin, S. (1985). The satisfaction with life scale. Journal of Personality Assessment, 49, 71-75. doi: https://doi. org/10.1207/s15327752jpa4901_13

Diener, E., Oishi, S., \& Lucas, R. E. (2009). Subjective well-being: The science of happiness and life satis- 
faction. In S. J. Lopez \& C. R. Snyder (Eds.), Oxford handbook of positive psychology (pp. 187-194). Oxford: Oxford University Press.

Ekas, N. V., Lickenbrock, D. M., \& Whitman, T. L. (2010). Optimism, social support, and well-being in mothers of children with autism spectrum disorder. Journal of Autism and Developmental Disorders, 40, 1274-1284. doi: https://doi.org/10.1007/ s10803-010-0986-y

Emmons, R. A. (2003). Personal goals, life meaning, and virtue: Wellsprings of a positive life. In C. Keyes \& J. Haidt (Eds.), Flourishing: Positive psychology and the well-lived life (pp. 105-128). Washington: American Psychological Association.

Erikson, E. H. (1968). Identity: Youth and crisis. New York: Norton.

Erikson, E. H. (1982). The life cycle completed. New York: Norton.

Ferguson, S. J., \& Goodwin, A. D. (2010). Optimism and well-being in older adults: The mediating role of social support and perceived control. The International Journal of Aging and Human Development, 71, 43-68. doi: https://doi.org/10.2190/AG.71.1.c

Frankl, V. E. (1969). The will to meaning: Principles and application of logotherapy. New York: New American Library.

Garcia, D. (2011). Two models of personality and well-being among adolescents. Personality and Individual Differences, 50, 1208-1212. doi: https://doi. org/10.1016/j.paid.2011.02.009

González-Carrasco, M., Casas, F., Malo, S., Viñas, F., \& Dinisman, T. (2017). Changes with age in subjective well-being through the adolescent years: Differences by gender. Journal of Happiness Studies, 18, 63-88. doi: https://doi.org/10.1007/s10902-016-9717-1

González-Carrasco, M., Casas, F., Viñas, F., Malo, S., Gras, M. E., \& Bedin, L. (2017). What leads subjective well-being to change throughout adolescence? An exploration of potential factors. Child Indicators Research, 10, 33-56. doi: https://doi. org/10.1007/s12187-015-9359-6

Ho, M. Y., Cheung, F. M., \& Cheung, S. F. (2010). The role of meaning in life and optimism in promoting well-being. Personality and Individual Differences, 48, 658-663. doi: https://doi.org/10.1016/j. paid.2010.01.008

Ju, H., Shin, J. W., Kim, C. W., Hyun, M. H., \& Park, J. W. (2013). Mediational effect of meaning in life on the relationship between optimism and well-being in community elderly. Archives of Gerontology and Geriatrics, 56(2), 309-313. doi: https://doi.org/10.1016/j. archger.2012.08.008

Karademas, E. C. (2006). Self-efficacy, social support and well-being: The mediating role of optimism. Personality and Individual Differences, 40, 1281-1290. doi: http://dx.doi.org/10.1016/j.paid.2005.10.019

King, L. A., Hicks, J. A., Krull, J. L., \& Del Gaiso, A. K. (2006). Positive affect and the experience of meaning in life. Journal of Personality and Social Psychology, 90, 179-196. doi: http://dx.doi. org/10.1037/0022-3514.90.1.179

Krok, D. (2014). The religious meaning system and subjective well-being: The mediational perspective of meaning in life. Archive for the Psychology of Religion, 36, 253-273. doi: http://dx.10.1163/1573612112341288

Krok, D. (2015a). The mediating role of optimism in the relations between sense of coherence, subjective and psychological well-being among late adolescents. Personality and Individual Differences, 85, 134-139. doi: https://doi.org/10.1016/j.paid.2015.05.006

Krok, D. (2015b). The role of meaning in life within the relations of religious coping and psychological wellbeing. Journal of Religion and Health, 54, 2292-2308. doi: https://doi.org/10.1007/s10943-014-9983-3

Machell, K. A., Kashdan, T. B., Short, J. L., \& Nezlek, J. B. (2015). Relationships between meaning in life, social and achievement events, and positive and negative affect in daily life. Journal of Personality, 83, 287-298. doi: https://doi.org/10.1111/jopy.12103

Orejudo, S., Puyuelo, M., Fernández-Turrado, T., \& Ramos, T. (2012). Optimism in adolescence: A crosssectional study of the influence of family and peer group variables on junior high school students. Personality and Individual Differences, 52, 812-817. doi: https://doi.org/10.1016/j.paid.2012.01.012

Pinquart, M. (2002). Creating and maintaining purpose in life in old age: A meta-analysis. Ageing International, 27, 90-114. doi: https://doi. org/10.1007/s12126-002-1004-2

Preacher, K. J., \& Hayes, A. F. (2008). Asymptotic and resampling strategies for assessing and comparing indirect effects in multiple mediator models. Behavior Research Methods, 40, 879-891. doi: https://doi.org/10.3758/BRM.40.3.879

Reker, G., \& Wong, P. T. P. (2012). Personal meaning in life and psychosocial adaptation in the later years. In P. T. P. Wong (Ed.), The human quest for meaning: Theories, research, and applications (pp. 433-456). London and New York: Routledge.

Ryff, C. D. (1989). Happiness is everything, or is it? Explorations on the meaning of psychological wellbeing. Journal of Personality and Social Psychology, 57, 1069-1081. doi: https://doi.10.1037/00223514.57.6.1069

Ryff, C. D., \& Singer, B. H. (2008). Know thyself and become what you are: A eudaimonic approach to psychological well-being. Journal of Happiness Studies, 9, 13-39. doi: https://doi.org/10.1007/ s10902-006-9019-0

Scheier, M. F., \& Carver, C. S. (2009). Optimism. In S. Lopez (Ed.), Encyclopedia of positive psychology (Vol. 2, pp. 656-663). Oxford, UK: Wiley-Blackwell.

Scheier, M. F., Carver, C. S., \& Bridges, M. W. (1994). Distinguishing optimism from neuroticism (and trait anxiety, self-mastery, and self-esteem): 
A reevaluation of the Life Orientation Test. Journal of Personality and Social Psychology, 67, 10631078. doi: http://dx.doi.org/10.1037/0022-3514.67. 6.1063

Seligman, M. E. (2012). Flourish: A visionary new understanding of happiness and well-being. New York: Free Press.

Shaffer, D., \& Kipp, K. (2013). Developmental psychology: Childhood and adolescence. Belmont: Cengage Learning.

Sheldon, K. M., \& Cooper, M. L. (2008). Goal striving within agentic and communal roles: Separate but functionally similar pathways to enhanced well-being. Journal of Personality, 76, 415-447. doi: https://doi.org/10.1111/j.1467-6494.2008.00491.x

Sheldon, K. M., \& Hoon, T. H. (2013). The multiple determination of well-being: Independent effects of positive traits, needs, goals, selves, social supports, and cultural contexts. In A. Delle Fave (Ed.), The exploration of happiness (pp. 141-160). Amsterdam: Springer Netherlands.

Sheldon, K. M., \& Houser-Marko, L. (2001). Self-concordance, goal attainment, and the pursuit of happiness: Can there be an upward spiral? Journal of Personality and Social Psychology, 80, 152-165. doi: 10.1037/0022-3514.80.1.152

Sheldon, K. M., Elliot, A. J., Ryan, R. M., Chirkov, V., Kim, Y., Wu, C., Demir, M., \& Sun, Z. (2004). Selfconcordance and subjective well-being in four cultures. Journal of Cross-Cultural Psychology, 35, 209223. doi: https://doi.org/10.1177/0022022103262245

Steger, M. F. (2009). Meaning in life. In S. J. Lopez \& C. R. Snyder (Eds.), Oxford handbook of positive psychology (pp. 679-687). Oxford, UK: Oxford University Press.

Steger, M. F. (2012). Making meaning in life. Psychological Inquiry, 23, 381-385. doi: https://doi.org/10. 1080/1047840X.2012.720832

Steger, M. F., Frazier, P., Oishi, S., \& Kaler, M. (2006). The meaning in life questionnaire: Assessing the presence of and search for meaning in life. Journal of Counseling Psychology, 53, 80-93. doi: 10.1037/0022-0167.53.1.80

Steger, M. F., Kashdan, T. B., Sullivan, B. A., \& Lorentz, D. (2008). Understanding the search for meaning in life: Personality, cognitive style, and the dynamic between seeking and experiencing meaning. Journal of Personality, 76, 199-228. doi: https://doi.org/10.1111/ j.1467-6494.2007.00484.x

Sulkers, E., Fleer, J., Brinksma, A., Roodbol, P. F., Kamps, W. A., Tissing, W. J., \& Sanderman, R. (2013). Dispositional optimism in adolescents with cancer: Differential associations of optimism and pessimism with positive and negative aspects of well-being. British Journal of Health Psychology, 18, 474-489. doi: https://doi.org/10.1111/j.2044-8287.2012.02096.x.

Thoits, P. A. (2012). Role-identity salience, purpose and meaning in life, and well-being among vol- unteers. Social Psychology Quarterly, 75, 360-384. doi: https://doi.org/10.1177/0190272512459662

Watson, D., \& Clark, L. A. (1994). The PANAS-X: Manual for the positive and negative affect schedule - expanded form. Iowa: The University of lowa. Retrieved from: http://ir.uiowa.edu/psychologypubs/11

Wong, P. T. P. (1998). Implicit theories of meaningful life and the development of the Personal Meaning Profile (PMP). In P. T. P. Wong \& P. Fry (Eds.). Handbook of personal meaning: Theory, research, and practice (pp. 111-140). Mahwah, NJ: Lawrence Erlbaum.

Wong, P. T. P. (2012). Toward a dual-systems model of what makes life worth living. In P. T. P. Wong (Ed.), The human quest for meaning: Theories, research, and applications (pp. 3-22). London and New York: Routledge. 